\title{
Succession of sessile organisms on experimental plates immersed in Nabeta Bay, Izu Peninsula, Japan*. II. Succession of invertebrates
}

\author{
Tetsu Hirata \\ Institute of Biological Sciences, University of Tsukuba, Sakura-mura, 305 Ibaraki, Japan
}

\begin{abstract}
The succession of sessile invertebrates over ca 3 yr was studied by suspending concrete plates at depths of 1.0, 2.5, 4.0 and $5.5 \mathrm{~m}$ in Nabeta Bay, Shimoda, Pacific coast of Japan. A total of 28 species of sessile invertebrates appeared during colonization. Their succession was divided into 3 stages by dendrogram analysis: Stage 1 is characterized by the earliest colonizers of the barnacle Balanus trigonus and the spirorbid Dexiospira foraminosus; Stage 2 by the ascidian Diplosoma mitsukurii; and Stage 3 by the oyster Crassostrea nippona. The earliest colonizers were overgrown by colonial ascidians, bryozoans and sponges recruiting a little later. The overgrowth of these colonists, especially D. mitsukuri, affected the subsequent community structure of sessile invertebrates. The pattern of transition of sessile invertebrates differed with depth. At depths of 1.0 and $2.5 \mathrm{~m}, \mathrm{C}$. nippona finally dominated by overgrowing other sessile invertebrates. Communities at these 2 depths reached Stage 3 between 13 and $37 \mathrm{mo}$ after immersion. At a depth of $4.0 \mathrm{~m}, \mathrm{C}$. nippona finally decreased in coverage, while B. trigonus, D. mitsukurii and the bryozoans Watersipora subovoidea and Amathia distans increased. The community at this depth reached Stage 3 after 13 to 37 mo from immersion. At a depth of $5.5 \mathrm{~m}, C$. nippona did not appear at all, but the barnacles Megabalanus volcano and $M$. rosa as well as $B$. trigonus, $D$. mitsukurii, W. subovoidea and $A$. distans increased in coverage 37 mo after immersion. At this depth, the community remained at Stage 2 during the period from 4 to 37 mo after immersion. In the period from 13 to 37 mo the number of species remained almost unchanged at depths of 1.0 and $2.5 \mathrm{~m}$, but tended to decrease at 4.0 and $5.5 \mathrm{~m}$. The communities at the 2 upper depths dominated by $C$. nippona were regarded as a persistent climax community in the succession, because $C$. nippona can settle easily on the shells of barnacles having high recruitment capability, it can avoid the intensive overgrowth by later colonists, and it has a long life span. On the other hand, the communities at the 2 lower depths dominated by colonial animals seem to inhibit the invasion of other sessile invertebrates through competition for space.
\end{abstract}

\section{INTRODUCTION}

Margalef (1968) and Odum (1969) have suggested that, in stable environments, community attributes such as species composition, metabolism and succession reach a mature stage dominated by $K$-selected species (species with slow development, relatively high competitive ability, late reproduction, large body size and low metabolic rates). However, this hypothesis remains controversial (Drury \& Nisbet 1973, Horn 1974, Connell \& Slatyer 1977).

- Contributions from the Shimoda Marine Research Center, No. 467
By suspending experimental plates in the subtidal zone, I studied the succession of sessile organisms from the changes of species replacement, community structure, community metabolism, community biomass and community maturity as described in the hypothesis of Margalef (1968) and Odum (1969).

The previous paper (Hirata 1986) described species replacement and changes in the number of species of algae during succession. The present paper describes corresponding changes for sessile invertebrates during succession. The relationship between species replacement and ecological characteristics of appearing invertebrates is discussed. Features and transitional patterns of 3 developmental stages obtained by dendrogram 
analysis are examined. Lastly, stability and persistence in the succession are discussed.

\section{MATERIALS AND METHODS}

The study site and environmental conditions have already been described in the first paper of the series (Hirata 1986). A total of 128 concrete plates $(20 \mathrm{~cm} \times 20$ $\mathrm{cm} \times 2 \mathrm{~cm}$ ) were submerged vertically at depths of 1.0 , $2.5,4.0$ and $5.5 \mathrm{~m}$ on 9 July 1974 . The method of setting of experimental plates in the sea and the method and time of sampling were the same as used in the first part of the series. The 4 depths at which the plates were kept are designated Depth $A, B, C$ and $D$, respectively. Immersion period from setting out plates until each sampling time is represented by the approximate number of elapsed months, i.e. 2, 4, 6, 10, 13, 26 and 37 mo.

The observations and estimation of percent cover of invertebrates on experimental plates were made, concurrently, by the same method as used in the study on algal succession (Hirata 1986). The percent cover of invertebrates was estimated in the central area $116 \mathrm{~cm}$ $\times 16 \mathrm{~cm}$ ) of plates because of a possible edge effect caused by sessile organisms or possible damage occurring during the experiment. Photographs of plates were projected onto $1 \mathrm{~cm} \times 1 \mathrm{~cm}$ graph paper, and the percent cover of each species was calculated by counting the number of squares occupied by the attachment sites of invertebrates.

\section{RESULTS}

\section{Species composition and percent cover}

Throughout the period from 2 to 37 mo after immersion, a total of 28 species of invertebrates were observed (Table 1). The barnacles Megabalanus volcano and $M$. rosa were counted as the same species because of difficulty in identifying their juveniles in the photographic analysis. The changes in mean cover (\%) of these 28 species over time are summarized in Table 1. The time of appearance of each species and change of its percent cover during succession are described below for each taxon.

\section{Cirripedia}

Balanus trigonus was found on all plates sampled. The percent cover of this species 2 mo after immersion was 97.9 to $100.0 \%$, higher at Depths $C$ and D than at $A$ and $B$. Its percent cover then decreased until 6 or 10 mo after immersion, but increased again 10 or 13 mo after immersion. At Depths A and B, though there was a slight increase in percent cover from 13 to 26 mo after immersion, the percent cover at 37 mo after immersion decreased to the lowest level of 79.8 or $87.6 \%$. On the other hand, at Depths $C$ and D, the percent cover decreased slightly 26 mo after immersion, and increased to 99.4 or $99.6 \% 37$ mo after immersion. The high values at Depths $C$ and $D$ were similar to those of younger plates immersed for 2 to $4 \mathrm{mo}$.

Megabalanus volcano and $M$. rosa were the earliest colonizers, like $B$. trigonus, but they showed much lower percent cover. Unlike $B$. trigonus their percent cover increased until 4 or 6 mo after immersion. At Depths $A$ and $B$, Megabalanus percent cover decreased successively to reach a minimum 37 mo after immersion. At Depths C and D, it temporarily increased 10 to 13 mo after immersion. It then decreased at Depth C, but increased 26 to 37 mo after immersion at Depth D. Another species, Balanus eburneus, was rare, being found only on one plate immersed for $4 \mathrm{mo}$

\section{Tunicata}

The tunicates identified were all colonial ascidians except for one species, Styela plicata. Botrylloides violaceus, Botrylloides simodensis, Botryllus primigenus, Symplegma reptans and Styela plicata appeared first in the period from 2 to 6 mo after immersion. The occurrence of these 5 species was restricted to the period from 2 to 13 mo after immersion. Though the percent cover of these species was generally low, $B$. violaceus and $B$. simodensis were somewhat higher in percent cover, especially 6 mo after immersion.

Diplosoma mitsukurii, Didemnum moseleyi and Trididemnum savignij often dominated plates. These 3 species appeared first 2 or 4 mo after immersion, and were continuously found until 37 mo after immersion. The percent cover of $D$. mitsukurii increased to a maximum of 61.6 to $77.4 \% 10$ mo after immersion at Depths A, B and C, and to $89.1 \%$ at 6 mo at Depth D. At 13 mo after immersion, its percent cover decreased to 9.6 to $47.7 \%$ at all depths. In the period from 13 to 37 mo after immersion, the percent cover decreased after an increase at Depth $A$, while it increased at Depths B, C and $D$. The percent cover at 37 mo after immersion showed a high value of $85.5 \%$ at Depth D. D. moseleyi showed its maximum percent cover of 24.2 to $50.1 \% 13$ or 26 mo after immersion, although by 37 mo after immersion it decreased to 5.3 to $21.1 \%$. This decrease was most obvious at Depths C and D. T. savignii showed a maximum percent cover of 12.8 to $32.2 \% 13$ or 26 mo after immersion at Depths $A_{1} B$ and $C$, whereas at 37 mo after immersion it had decreased to 


\begin{tabular}{|c|c|c|c|c|c|c|}
\hline 0 & $\stackrel{\circ}{S} \circ \bar{N}$ & $0000 \stackrel{\substack{n \\
\infty \\
\infty}}{n} 0000$ & 800 & $\stackrel{\infty}{\infty} 00000 \begin{array}{c}\infty \\
\infty \\
\infty\end{array}$ & mo & 000 \\
\hline$\stackrel{\circ}{E}^{U}$ & gom & $0000 \stackrel{0}{n} n^{n} \stackrel{\infty}{0}_{0}^{0} 000$ & Too & $\underset{m}{2} 0000 \stackrel{m}{8}$ & $\stackrel{\infty}{-}$ & $00 \frac{4}{2}$ \\
\hline $\bar{m}_{\infty}$ & $\stackrel{\infty}{\infty} \circ \stackrel{\circ}{-1}$ & 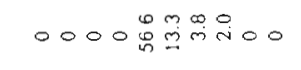 & $\because 0=$ & ڤై & लं: & $\stackrel{\infty}{N} \circ \underset{\text { in }}{n}$ \\
\hline$\varangle$ & 我。? & 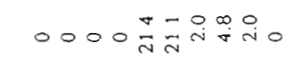 & 000 & $\therefore 0000 \stackrel{0}{\%}$ & $\simeq \Xi_{0}^{\circ}$ & 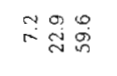 \\
\hline$\circ$ & $\tilde{G}_{0}^{\circ} 0^{\top}$ & 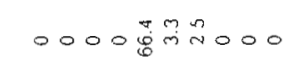 & i্ & mo $000 \stackrel{9}{9}$ & ○。 & 000 \\
\hline$\stackrel{\circ}{\xi}^{u}$ & $n_{n}^{n} \circ \hat{i}$ & 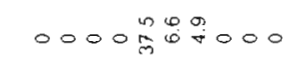 & 峁○。 & $\stackrel{m}{\rightleftarrows} 0000 \stackrel{\infty}{\pi}$ & $: \square$ & oD莒 \\
\hline$\stackrel{\phi}{\infty}_{\infty}$ & $\underset{\infty}{\infty} \circ=$ & 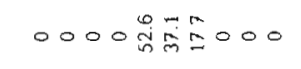 & Dioo & 00000 每 & $\infty$ & 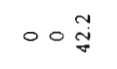 \\
\hline$<$ & 0 & $0000 \stackrel{0}{0} \mathrm{~A} \infty 000$ & \&oo & 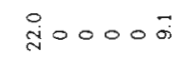 & $\stackrel{m}{\circ}$ & 象怘 \\
\hline 口 & $\underset{\infty}{\infty} \circ \underset{\infty}{\infty}$ & 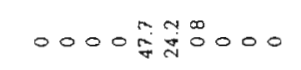 & inoo & 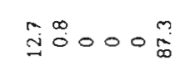 & $\stackrel{2}{\circ}$ & 000 \\
\hline$\stackrel{\circ}{ }^{u}$ & 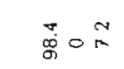 & 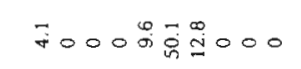 & So & 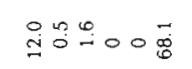 & $\stackrel{5}{\circ}: 0$ & $0 \overline{0}: 00$ \\
\hline$=\infty$ & 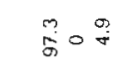 & 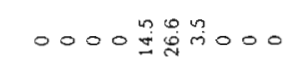 & $\stackrel{\infty}{\infty}_{\infty}^{\infty}$ & $\underset{m}{\infty} 0000 \stackrel{N}{m}$ & no & ○ लm \\
\hline$\varangle$ & $\bar{j} \circ:$ & 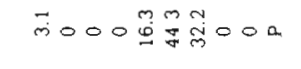 & Noo & 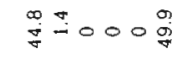 & $\stackrel{m}{-} 0$ & o ํㅛㅇ \\
\hline 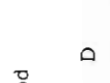 & $\prod_{0}^{\infty} 00$ & 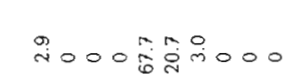 & ०के & 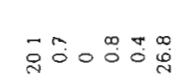 & $\because 0$ & 000 \\
\hline 帝 & 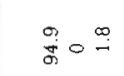 & 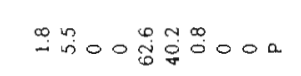 & 足 & :0000 స̃ & $\therefore 0$ & $0 \ddot{0}$ \\
\hline 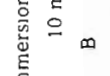 & $\stackrel{\circ}{\circ}=\stackrel{m}{\infty}$ & 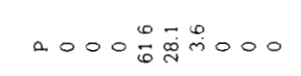 & $=\stackrel{n}{N}$ & $m 0^{\infty} 000^{\infty}$ & $\begin{array}{l}\infty \\
\infty \\
\infty\end{array}$ & 000 \\
\hline$\underline{\xi} \quad \varangle$ & $\underset{\tilde{\sigma}}{\infty} \infty \infty$ & 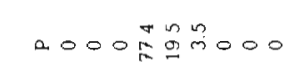 & 000 & 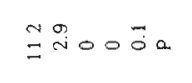 & $\infty_{0}^{\infty}$ & a. $\ddot{0}$ \\
\hline$\circ$ & $\begin{array}{ll}2 \\
2\end{array}$ & 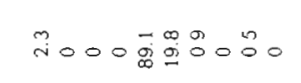 & $\bar{i} 00$ & 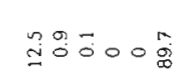 & $\stackrel{\circ}{i}$ & 000 \\
\hline$\stackrel{\circ}{0}^{u}$ & $\$$ & 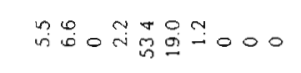 & 300 & 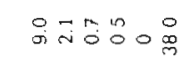 & $\stackrel{m}{=0}$ & $\circ \stackrel{\infty}{0} 0$ \\
\hline 焉 & ஸ். & 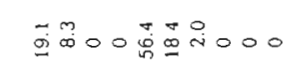 & $\stackrel{0}{i} 0$ & $\frac{9}{2} \pi 000$ & o & $= \pm 0$ \\
\hline$\ll$ & 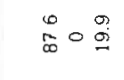 & 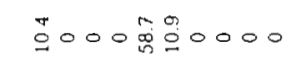 & s. & 实 & iso & $\because 200$ \\
\hline 0 & $\stackrel{\circ}{\circ} \circ m$ & 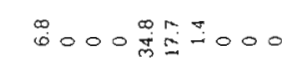 & moo & $\stackrel{m}{0} 00000$ & $\overrightarrow{\text { NO }}$ & 000 \\
\hline$\stackrel{8}{ }^{U}$ & $\begin{array}{l}\infty \\
\infty \\
m\end{array}$ & 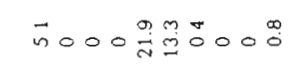 & 000 & \pm 00000 & $\stackrel{\infty}{-} \stackrel{+}{0}$ & 000 \\
\hline$\stackrel{E}{*}$ & $\stackrel{\infty}{\infty} \circ \stackrel{\infty}{\infty}$ & OొO & $\therefore 00$ & i⿱ & $m=$ & 000 \\
\hline$\varangle$ & $\underset{\infty}{\infty} \circ \hat{9}$ & $\stackrel{\infty}{=} \circ \stackrel{m}{-} \circ \stackrel{m}{\mathrm{~m}}=\stackrel{\infty}{=} 000$ & 030 & $\overline{\mathrm{d}}=\overline{0} 000$ & $n_{0}$ & 000 \\
\hline 口 & $\stackrel{\circ}{\circ} \circ$ & 0000000000 & 000 & 000000 & $\circ \stackrel{\sim}{\sim}$ & 000 \\
\hline$\stackrel{\circ}{E}^{u}$ & $\stackrel{\circ}{\circ} \circ=$ & 0000000000 & 000 & $\vec{i} 00000$ & $\circ \bar{i}$ & 000 \\
\hline 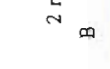 & 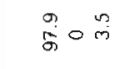 & $00 \pm 000 m 000$ & 000 & ji 00000 & $\circ \overrightarrow{\underline{I}}$ & 000 \\
\hline$\varangle$ & $\stackrel{\circ}{8} \circ \stackrel{0}{0}$ & $\begin{array}{c}0000000000 \\
\varepsilon\end{array}$ & 000 & 000000 & 0 & 000 \\
\hline $\begin{array}{l}\tilde{\tilde{u}} \\
\tilde{\ddot{\omega}} \\
\tilde{\omega}\end{array}$ & 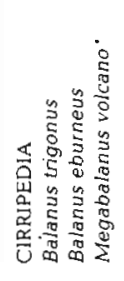 & 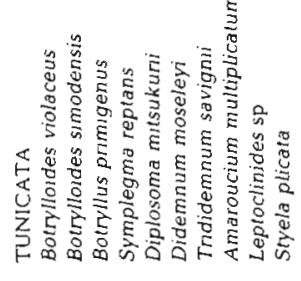 & 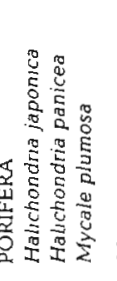 & 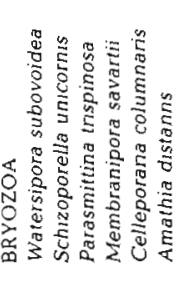 & 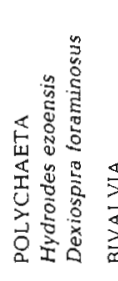 & 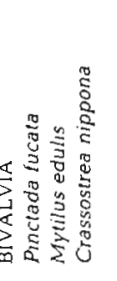 \\
\hline
\end{tabular}


0.8 to $3.8 \%$ at these depths. At Depth $D$, this species showed low percent cover throughout the study period, and was absent 37 mo after immersion.

Amaroucium multiplicatum and Leptoclinides sp. were rare, being found only at Depth $A$ or B 37 mo after immersion and on one of Depth D plates immersed for 6 mo.

\section{Porifera}

Halichondria japonica appeared first 4 or 6 mo after immersion. Though this species was found on only one of the Depth B plates 10 mo after immersion, it occurred at all depths 13 mo after immersion. Its percent cover showed a maximum 26 mo after immersion, much higher at Depths C and D. At $37 \mathrm{mo}$, it was not found at Depth A but showed low percent cover at Depths B, C and D. Halichondria panicea was transiently found 4 and 10 mo after immersion, appearing earlier at Depths $\mathrm{A}$ and $\mathrm{B}$ and later at Depths $\mathrm{C}$ and D. Mycale plumosa was rare, being found on one of Depth $B$ plates immersed for $37 \mathrm{mo}$.

\section{Bryozoa}

The bryozoans identified were of encrusting type except for Amathia distans which has a stoloniferous form. Watersipora subovoidea was found at all sampling times and usually dominated the plates. This species appeared first 2 or 4 mo after immersion. At Depths $A$ and $B$, though there was a transient decrease in percent cover 10 mo after immersion, its percent cover increased to reach a highest value of 39.8 or $44.8 \% 13$ mo after immersion. At Depths $C$ and $D$, percent cover did not show such a high value at this time. In the period from 13 to 37 mo after immersion, percent cover decreased at Depth $A$, but increased greatly 26 to 37 mo after immersion at Depths $B, C$ and D. Percent cover at 37 mo after immersion showed a gradual increase with depth. Depth D plates immersed for 37 mo showed a maximum percent cover of $82.8 \%$.

Amathia distans often dominated the plates, like Watersipora subovoidea. This species appeared first 6 mo after immersion at Depths C and D, and later, 10 mo after immersion, at Depths $A$ and $B$. It was continuously present until 37 mo after immersion. Percent cover at 13 mo after immersion reached a maximum or was close to it, being higher at Depths $C$ and D. Percent cover temporarily decreased 26 mo after immersion, but increased again 37 mo after immersion, being especially high at Depths $C$ and D.

Schizoporella unicornis appeared first 4 or 6 mo after immersion. This species was continuously observed until 13 mo after immersion, but was absent 26 and 37 mo after immersion. Parasmittina trispinosa, Mem- branipora savartii and Celleporaria columnaris appeared first on the plates immersed for 4 or 6,6 or 10 , and 10 mo, respectively. These 3 species were transient and restricted also to the period of 4 to 13 mo after immersion.

\section{Polychaeta}

The serpulid Hydroides ezoensis first appeared $4 \mathrm{mo}$ after immersion. Its percent cover showed a maximum 10 mo after immersion though there was a decrease 6 mo after immersion. This species was continuously present until 37 mo after immersion at Depths A, B and $C$, where the percent cover increased 26 to 37 mo after immersion. At Depth $\mathrm{D}$, though absent 13 and 26 mo after immersion, it reappeared 37 mo after immersion.

The spirorbid Dexiospira foraminosus appeared first 2 mo after immersion, when percent cover was higher at greater depths. This species was not found on the plates immersed for 6 mo. Nevertheless, it reappeared 26 mo after immersion at Depth A, 37 mo after immersion at Depth $B$, and earlier at 13 mo after immersion at Depths $C$ and D. After that, it disappeared at Depths $C$ and $D$, earlier at the latter depth.

\section{Bivalvia}

Pinctada fucata, Mytilus edulis and Crassostrea nippona become fairly large at maturity. $P$. fucata appeared only at Depths A and B. It appeared first on one of Depth A plates immersed for 6 mo. Though not found 13 and 26 mo after immersion, it was present on 2 of 3 Depth A plates and 1 of 3 Depth B ones 37 mo after immersion.

Mytilus edulis appeared at Depths A, B and C. It appeared first on Depth $A$ to $C$ plates immersed for 6 mo, but its percent cover decreased temporarily $10 \mathrm{mo}$ after immersion. Subsequently, the percent cover increased to reach $22.9 \% 37$ mo after immersion at Depth $A$, but this species was not found at all by 26 and 37 mo after immersion at Depths $B$ and $C$.

Crassostrea nippona appeared also at Depths A, B and $C$. It appeared first on one of the Depth A plates immersed for $10 \mathrm{mo}$ and by $13 \mathrm{mo}$, it was found on all plates at Depths A and B and on one plate at Depth C. The percent cover at 37 mo after immersion increased to 59.6 or $52.5 \%$ at Depths A and B, while it decreased to $21.7 \%$ at Depth $\mathrm{C}$ after having reached a maximum of $50.4 \% 26$ mo after immersion.

\section{Changes in the number of species}

Temporal changes in the number of species are shown in Fig. 1. To confirm statistically the trend of the 

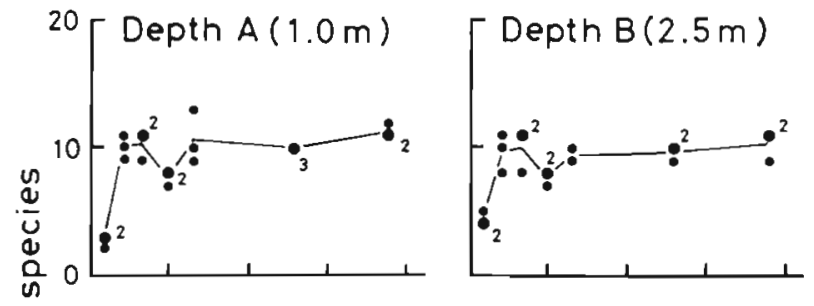

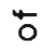

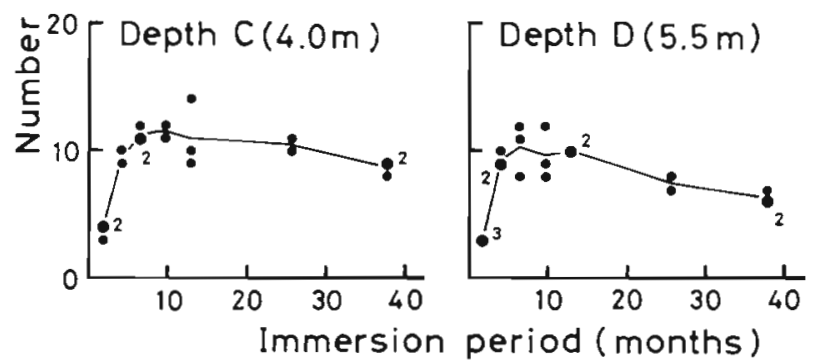

Fig. 1. Changes in the number of species in the central areas $(16 \mathrm{~cm} \times 16 \mathrm{~cm})$ of plates during community development at 4 depths. Curves show average number of species present per plate. Small solid circle represents a measurement for an individual plate; large solid circle represents 2 or 3 samples having the same number of species. Numbers near them indicate number of samples

changes with time, Spearman's rank correlation coefficients of the number of species on time were obtained for 3 sample periods which were arbitrarily assigned according to the pattern of the changes. The colonization of sessile invertebrates proceeded rapidly on submerging the experimental plates, and the number of species increased rapidly to reach a maximum on average 6 mo after immersion (Fig. 1). Spearman's rank correlation coefficients were significantly positive during the period from 2 to 6 mo after immersion at all depths. But, in the period from 6 to 13 mo after immersion, there was no significant correlation (Table 2). In this period, the pattern of change in the number of species differed with depth: there was a decrease in the number of species 10 mo after immersion at Depths $A$ and $B$, while no decrease at Depths $C$ and D. As to the period from 13 to 37 mo after immersion, the number of species remained almost unchanged at Depths $A$ and $B$, while it showed a tendency to decrease at Depths C and D (Fig. 1). This decrease was significant at Depth D (Table 2).

\section{DISCUSSION}

Physical or biological disturbance, such as caused by log damage, storm waves, scouring, sedimentation, grazing or predation, has been known to affect the community structure of sessile organisms (e.g. McDougall 1943, Aleem 1957, Stephenson \& Searles 1960, Bakus 1966, Dayton 1971, Foster 1975). None of the plates examined had come in contact with the sand bottom but only with ropes supporting them, so that predators common on neighboring rocky reefs, such as starfish, crabs and snails, except for juveniles, were rarely observed on plates. By underwater observations during the day, I confirmed that the following predators were foraging near the raft which carried the plates: surgeon-fishes Navodon modestus and Stephanolepis cirrhifer, blowfish Ostracion cubicus, and young of false parrot fish Oplegnathus fasciatus. The predatory fish were observed in the warmer season from late spring to mid autumn. However, they were believed to have little influence on the present community structure of sessile organisms. Further, grazing by sea urchins or snails common on neighboring rocky reefs was negligible for the same reason as the case of predators. However the scouring of sand from the bottom seems to have had some effect on the community structure of sessile invertebrates as was also the case with the algal community (Hirata 1986).

\section{Community development and ecological characteristics of sessile invertebrates}

It is well known that overgrowth by sessile invertebrates is an important factor affecting the community structure of sessile organisms (e.g. McDougall 1943, Scheer 1945, Hoshiai 1959, 1960, 1965). The succession of sessile invertebrates is also influenced by the ecological characteristics of sessile invertebrates such as their size, life form, reproduction, growth rate, life span, robustness of tissue or shell, and ability to avoid overgrowth by other sessile organisms.

\section{Transition of early colonizing solitary species}

Of the earliest colonizers, Balanus trigonus, Megabalanus volcano, $M$. rosa and Dexiospira foraminosus have a solitary form, and are replaced later in the

Table 2. Spearman's rank correlation coefficients showing the tendency of changes in the number of species in the central area $(16 \mathrm{~cm} \times 16 \mathrm{~cm}$ ) of plates. Sample size (number of plates examined) is shown in parentheses. ' Highly significant $(p<0.01)_{i} \cdot$ significant $(p<0.05) ;$ ns: not significant $(\mathrm{p}>0.05)$

\begin{tabular}{|lrrr|}
\hline Depth & \multicolumn{3}{c|}{ Immersion period (mo) } \\
& $2-6$ & $6-13$ & \multicolumn{1}{c|}{$13-37$} \\
\hline A $(1.0 \mathrm{~m})$ & $0.780(9)^{\circ}$ & $0.000(9) \mathrm{ns}$ & $0.415(9) \mathrm{ns}$ \\
$\mathrm{B}(2.5 \mathrm{~m})$ & $0.782(9)^{\circ}$ & $-0.273(8) \mathrm{ns}$ & $0.413(8) \mathrm{ns}$ \\
$\mathrm{C}(4.0 \mathrm{~m})$ & $0.824(8)^{\circ}$ & $-0.227(8) \mathrm{ns}$ & $-0.617(8) \mathrm{ns}$ \\
$\mathrm{D}(5.5 \mathrm{~m})$ & $0.808(9)^{\circ} \cdot$ & $-0.115(8) \mathrm{ns}$ & $-0.923(7)^{\cdots}$ \\
\hline
\end{tabular}


succession by overgrowth of later-appearing colonial ascidians, bryozoans, and sponges (Table 1). The decrease in percent cover of $B$. trigonus at 6 or 10 mo after immersion was primarily due to overgrowth by later-appearing colonists, and secondarily due to predation by the polyclad Pseudostylochus sp., which was frequently observed in the shells of barnacles. The increase in percent cover of $B$. trigonus at 13 mo after immersion is attributable to an abundant recruitment in summer (Table 1). The percent cover of $M$. volcano and $M$. rosa increased until 6 mo after immersion. These 2 species grow larger than $B$. trigonus, and thus tend to escape overgrowth by later-appearing colonists. Overgrowth by colonists also caused the disappearance of the small sized $D$. foraminosus from the plates immersed for 6 mo (Table 1).

Osman (1977) suggested a hierarchy in interspecific competition among several species of sessile invertebrates, in which solitary species of limited size (e.g. Balanus amphitrite niveus and Spirorbis pagenstecheri) were easily overgrown by ascidians, bryozoans and sponges. A similar succession occurs in Nabeta Bay with the earliest colonizers of 4 species being replaced by later-appearing colonists. Complete disappearance from the plates did not necessarily occur. Thus, the barnacles B. trigonus, $M$. volcano and $M$. rosa were found on the plates from the start to the end of this study. The spirorbid Dexiospira foraminosus reappeared in the period from 13 to 37 mo after immersion (Table 1). The incomplete disappearance of these 4 species seems to be due to their abundant recruitment, and to free space created secondarily on the shells of Crassostrea nippona, Mytilus edulis and Pinctada fucata which eventually provided 3-dimensional space on the plates at Depths A and B.

Hydroides ezoensis, an early colonizer, was found even at 6 or 10 mo after immersion when Dexiospira foraminosus was not found at all. This species often escaped overgrowth successfully, aided by its calcareous tubes which were extended linearly and kept the open feeding end of the tube ahead of an overgrowing species as observed by Osman (1977). Another species of early colonizers, the ascidian Styela plicata, was found only within the first year after immersion. This species may have sloughed off from the plates as observed by Sutherland (1974, 1978), Sutherland \& Karlson (1977) and Mook (1981).

\section{Transition of later-colonizing colonial species}

Colonial ascidians, sponges and bryozoans can be classified into 3 successional groups according to the pattern of their appearances. The first group includes those species which appeared in the period from 2 to 13 mo after immersion. The second group includes those species which were continuously found from the first appearance until the end of the present study. The third group includes those species which appeared mainly 37 mo after immersion.

Colonial ascidians can be classified into the second or third group. Diplosoma mitsukurii belonging to the second group showed a maximum percent cover 6 or 10 mo after immersion because of spreading quickly on plates by high growth rate. But the percent cover of this species decreased at 13 mo after immersion of August when water temperature was maximum (Table 1). The season of sexual reproduction of $D$. mitsukuri seems to be year-round centering on the period from June to August (Kitazawa 1967, Yamaguchi 1975, Iwaki et al. 1977, Tsuchiya \& Osanai 1978). The decrease in percent cover of $D$. mitsukurii in summer may be due to the atrophy of vegetative growth as a result of the aging of the colonies after sexual reproduction. Didemnum moseleyi and Trididemnum savignii showed high percent cover 10 or 13 mo after immersion which is later than D. mitsukurii (Table 1). These 2 species grow more slowly than does $D$. mitsukurii, but they have a robust tunic containing hard spicules. Their robust tunics may have ensured their presence during the present study. These 3 species of ascidians belonging to the second group play an important role in the present community structure because of their intensive overgrowing capabilities. Amaroucium multiplicatum and Leptoclinides sp. belong to the third group (Table 1).

Sponges can be classified into 3 successional groups: Halichondria panicea appears to have been unable to avoid overgrowth because it appeared only at 4 and 10 mo after immersion; Halichondria japonica appears to have been able to avoid overgrowth because this species was present until 37 mo after immersion; Mycale plumosa was a later colonizer, being found only 37 mo after immersion (Table 1).

Bryozoans belong to the first or second group. Watersipora subovoidea and Amathia distans frequently showed high percent cover (Table 1). The percent cover of $W$. subovoidea decreased 6 or 10 mo after immersion at Depths $A$ and B, and a little later 13 mo after immersion at Depth D, while it remained low at Depth C (Table 1). This decrease in percent cover is primarily attributable to overgrowth of Diplosoma mitsukurii. The intensive overgrowth by $D$. mitsukurii is considered to have brought a temporary decrease in the number of species 10 mo after immersion at Depths $A$ and $B$ which were not observed at Depths $C$ and D (Fig, 1). On the other hand, the percent cover of $D$. mitsukurii decreased in the summer at 13 mo after immersion. This decrease brought an increase in percent cover of $W$. subovoidea and $A$. distans (Table 1). 
However, the percent cover of $D$. mitsukurii did not decrease greatly at this time at Depth D, presumably because lower water temperature at greater depths would have delayed the sexual reproduction of this species. At this depth, the percent cover of $W$. subovoidea was lower, while that of $A$. distans was higher (Table 1). These 2 species differ in life form: the former is encrusting, the latter stoloniferous. A. distans was found abundantly on the holdfasts of the kelp Eisenia bicyclis which was found only on Depth $C$ and D plates immersed for 13 mo (Hirata 1986). Bryozoans observed differ in the first time of appearance. The earliest species appeared 2 or 4 mo after immersion, the latest ones 10 mo after immersion: $W$. subovoidea, Schizoporella unicornis, Parasmittina trispinosa, Membranipora savartii, A. distans, and Celleporaria columnaris appeared in this order (Table 1). The reason for the differences in first time of appearance is not clear.

Classification of colonial ascidians, sponges and bryozoans into 3 groups according to their successional pattern seems to reflect differences in their growth rates or reproductive ability. Species belonging to the first group have lower growth rates, and some produce abundant recruits but others few, during the season of sexual reproduction. On the other hand, species belonging to the second group have higher growth rates and good recruitment. Therefore, the latter could outcompete the former species by overgrowing them within the first year after immersion. The occurrence of species of the third group at Depths A and B 37 mo after immersion may be due to the rarity of their larvae at the study site. Furthermore, the communities at Depths A and $\mathrm{B}$ were dominated by the kelp Eisenia bicyclis (Hirata 1986) as well as the oyster Crassostrea nippona. The algal canopy and shell respectively cause shading effects and create free space on the plates. It is inferred that these 2 factors together are necessary for the settlement of the species of the third group.

\section{Transition of later-colonizing solitary species}

The bivalves Pinctada fucata, Mytilus edulis and Crassostrea nippona recruited comparatively late within the first year of immersion; C. nippona was the latest (Table 1). These 3 species settled and grew on barnacles, and finally dominated Depth $\mathrm{A}$ and $\mathrm{B}$ plates immersed for $37 \mathrm{mo}$. Therefore, they are considered to have the ability to escape overgrowth by other sessile organisms present. The first and second species can detach themselves from their byssi and move from the site of original attachment. Valve movements of the bivalves are also considered to prevent overgrowth by potential overgrowing species. In the first year after immersion, P. fucata appeared sporadically, and per- cent cover of $M$. edulis decreased temporarily 10 mo after immersion (Table 1). This discontinuous appearance or decrease in percent cover of these 2 bivalves may be due to intensive overgrowth by colonial species as well as their slow growth rates and poor recruitment.

Pinctada fucata appeared again at Depths A and B 37 mo after immersion (Table 1). This suggests that the complicated surface structure of Crassostrea nippona is necessary for the establishment and survival of $P$. fucata. Mytilus edulis existed only at Depth A 26 and 37 mo after immersion. This may indicate that other depths are not suitable for its survival because its natural distribution is generally restricted to the range from the intertidal to the shallower subtidal zone. $C$. nippona can grow to have a massive and robust shell and thus escape overgrowth. C. nippona has the following characteristics advantageous for its survival: robust shell, great adhesive power to the substratum, great opening and closing power of each valve, and a long life span. Because of its longevity, the domination of C. nippona at Depths A and B lasted for a considerable time. The life span of $C$. nippona is not certain, but I confirmed it could live for more than $10 \mathrm{yr}$.

\section{Stages in community development inferred from dendrogram analysis}

To discriminate successive stages of community development, the samples were subjected to cluster analysis using Horn's coefficient of similarity (Horn 1966), based on Shannon-Wiener information theory and the weighted group average method. The data used for this analysis were mean percent cover of sessile invertebrates in the central area of plates. The results of analysis are shown as a dendrogram in Fig. 2, in which 3 major clusters can be discriminated. The level of percentage similarity for this division was arbitrarily determined to be between 74.3 and $81.1 \%$ (Fig. 2). The samples were generally clustered with time, but Depth D samples immersed for 6 to 37 mo formed a sub-cluster similar to the Depth $\mathrm{A}$ to $\mathrm{C}$ ones immersed for 4 to 10 mo rather than those immersed for 13 to $37 \mathrm{mo}$. This indicates that these Depth D samples are at an initial stage of succession. The 13D sample was closer to the $6 \mathrm{D}$ sample than $10 \mathrm{D}$ sample, showing a return to an early stage of succession. The $26 \mathrm{D}$ and $37 \mathrm{D}$ samples were different from younger Depth D samples immersed for 6 to $13 \mathrm{mo}$, and this is interpreted as a recovery from the initial stage of succession. On the other hand, Depth A to $\mathrm{C}$ samples immersed for 13 to $37 \mathrm{mo}$, which were clustered together, were evidently different from those immersed for 2 to $10 \mathrm{mo}$. This indicates that the older samples are at a later stage of succession. Of these, the 26 and 37 mo samples 


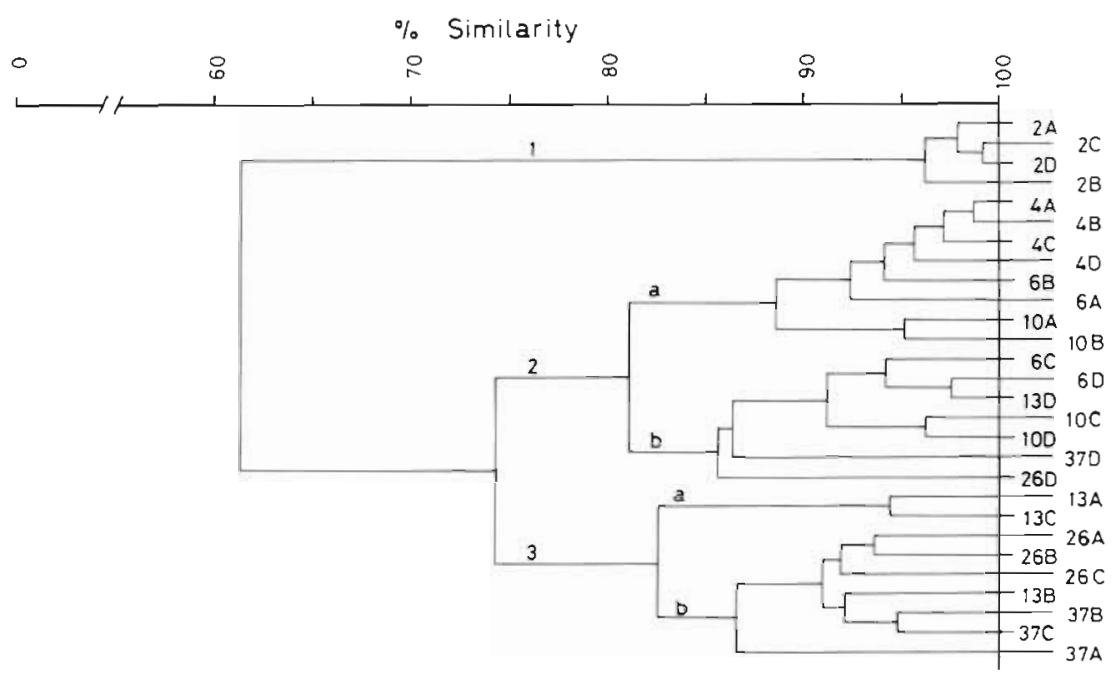

Fig. 2. Dendrogram constructed from Horn's similarity coefficients based on the mean percent cover of sessile invertebrates in the central area $(16 \mathrm{~cm} \times 16$ $\mathrm{cm}$ ) of a plate at each immersion period and depth. Major clusters are indicated by numbers and sub-clusters by letters. Samples are indicated at right by months and their immersed depth (e.g. 2A indicates the sample immersed for 2 mo at Depth A). See text for further explanation

formed a distinct sub-cluster. In it, the $37 \mathrm{~A}$ sample was different from the other samples, indicating that it is probably at a later stage of succession.

In the following discussion, the 3 major clusters (Fig. 2) were regarded as 3 stages in succession. Based on the results of this analysis, the samples can also be arranged according to depth and time and partitioned into the 3 stages as shown in Fig. 3. As seen in this diagram, Depth A to $C$ communities shifted successively from Stage 1 to Stages 2 and 3 with time. In Stage 3, Depth A to $C$ samples immersed for 26 and 37 mo were in one sub-cluster together. However the Depth D community shifted from Stage 1 to Stage 2 without advancing to Stage 3, remaining at Stage 2 throughout the period from 4 to 37 mo after immersion. In Stage 2, Depth D samples immersed for 6 to $37 \mathrm{mo}$ were in one sub-cluster (Fig. 3). This long period at Stage 2 is considered to have been caused by scouring of bottom sand.

\section{Features of developmental stages}

Features of the 3 stages distinguished in this study are summarized in Table 3. Each stage is characterized by the species which occupied the top to third rank in the mean percent cover of species in the central area of plates at each immersion period and depth. In all samples, Balanus trigonus always occupied the top rank.

In Stage 1, Dexiospira foraminosus was sub-dominant, always occupying the second rank; Megabalanus volcano and $M$. rosa were next dominant species, occupying the third rank except in one sample. Samples at this stage had a thin, uneven surface structure formed by the shells of barnacles. This stage is characterized by early colonizers, especially Balanus trigonus and $D$. foraminosus.
In Stage 2, Diplosoma mitsukurii was sub-dominant, always occupying the second or third rank; Watersipora subovoidea and Didemnum moseleyi dominated next, occupying the third to fifth rank except for 2 samples. Though the rank of domination of Amathia distans was low, this species occupied the second to fourth rank whenever it appeared. Samples at this stage have the sheets of colonials formed on the shells of barnacles. This stage is characterized by $D$. mitsukurii.

In Stage 3, Crassostrea nippona was sub-dominant. Didemnum mitsukurii and Amathia distans were the next dominant species, and their mean percent cover was similar to that of C. nippona. Following these 3 species, D. moseleyi and Watersipora subovoidea

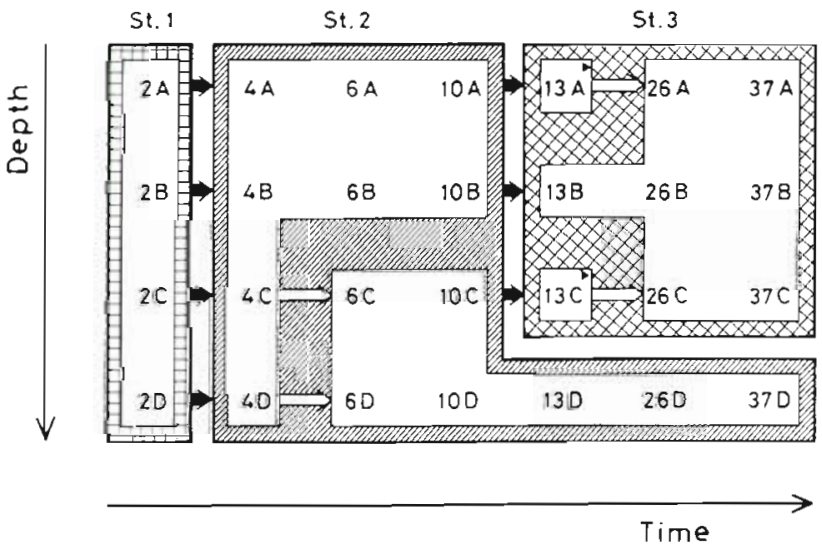

Fig. 3. Diagram showing the processes of community development at 4 depths, inferred from the results of dendrogram analysis shown in Fig. 2. Three kinds of hatched areas represent 3 developmental stages divided by the dendrogram analysis. Areas without hatching represent sub-clusters. The triangles on the right-hand corner of 2 boxes represent the same sub-cluster Black arrows indicate transition from one developmental stage to the next. White arrows indicate transition trom one sub-cluster to the other. Code as in Fig. 2 
occupied subordinate positions and were similar to each other in mean cover. Plates at this stage had a massive, rough surface structure formed by the shell of C. nippona, on which there was the overgrowth of sessile invertebrates mainly consisting of barnacles, ascidians and bryozoans. Especially the $37 \mathrm{~A}$ sample consisted of double layers of $C$. nippona.

\section{Stability and persistence in succession}

The oyster often forms an assemblage with many associated animals on underwater stones or rocky reefs (Möbius 1877, Tsuchiya \& Hirano 1985). As to the succession of communities of sessile invertebrates, there have been few studies dealing with domination by oysters. On the other hand, domination by mussels has been reported by many studies since the investigation by Hewatt (1935). The mussel remains dominant on rocky reefs by the occupation of space through overgrowing other species and inhibiting the colonization of other sessile species, when physical or biological disturbance is not effective (Paine 1966, 1971, 1974 , Dayton 1971, Menge 1976). In the present study, an assemblage dominated by Crassostrea nippona was

Table 3. Developmental stages derived from the dendrogram analysis shown in Fig. 2. Each stage is characterized by the species which occupied the top to third rank in mean percent cover. The degree of domination is ranked by the average of the 2 ranks of mean percent cover and frequency of appearance. Numerator: number of samples in which sessile invertebrates were observed. Denominator: total number of samples

\begin{tabular}{|c|c|c|c|c|}
\hline Stage & $\begin{array}{l}\text { Species which } \\
\text { occupied the top } \\
\text { to third rank }\end{array}$ & $\begin{array}{l}\text { Mean } \\
\text { percent } \\
\text { cover }\end{array}$ & $\begin{array}{l}\text { Appear- } \\
\text { ance } \\
\text { fre- } \\
\text { quency }\end{array}$ & $\begin{array}{l}\text { Rank } \\
\text { of } \\
\text { domi- } \\
\text { nation }\end{array}$ \\
\hline \multirow{5}{*}{1} & Balanus trigonus & 99.5 & $4 / 4$ & 1 \\
\hline & Dexiospira foraminosus & 16.7 & $4 / 4$ & 2 \\
\hline & Megabalanus volcano ${ }^{*}$ & 1.9 & $4 / 4$ & 3 \\
\hline & Watersipora subovoidea & 1.4 & $2 / 4$ & 4 \\
\hline & Trididemnum savignii & 0.9 & $1 / 4$ & 5 \\
\hline \multirow[t]{6}{*}{2} & Balanus trigonus & 95.6 & $15 / 15$ & 1 \\
\hline & Diplosoma mitsukurii & 56.2 & $15 / 15$ & 2 \\
\hline & Watersipora subovoidea & 19.3 & $15 / 15$ & 3 \\
\hline & Didemnum moseleyi & 18.0 & $15 / 15$ & 4 \\
\hline & Amathia distans & 22.3 & $8 / 15$ & 5 \\
\hline & Halichondria japonica & 3.7 & $9 / 15$ & 6 \\
\hline \multirow[t]{6}{*}{3} & Balanus trigonus & 94.1 & $9 / 9$ & 1 \\
\hline & Crassostrea nippona & 37.9 & $9 / 9$ & 2 \\
\hline & Diplosoma mitsukurii & 35.3 & $9 / 9$ & 3 \\
\hline & Amathia distans & 35.1 & $9 / 9$ & 4 \\
\hline & Didemnum moseleyi & 25.3 & $9 / 9$ & 5 \\
\hline & Watersipora subovoidea & 23.0 & $9 / 9$ & 6 \\
\hline
\end{tabular}

found at Depths A and B where there was no effective disturbance such as scouring by the bottom sand. On the other hand, at Depths C and D where such physical disturbance acted effectively, the domination by $C$. nippona never occurred, and the barnacle Balanus trigonus and colonial species Diplosoma mitsukurii, Watersipora subovoidea and Amathia distans increased in percent cover (Table 1). The number of species at Depths $A$ and $B$ remained almost unchanged in the period from 13 to 37 mo after immersion, while that at Depths $C$ and D showed a tendency to decrease in this period (Fig. 1, Table 2). Moreover, though samples immersed for 13 to 37 mo were not divided into 2 stages distinctly between Depths B and C in Fig. 3, the species which occupied high ranks in Stage 3 showed mean percent cover similar to one another, except for $B$. trigonus, while those in Stage 1 showed extreme domination by $B$. trigonus (Table 3 ). These facts suggest that communities at the surface are stable in community structure during this period in addition to tending toward an equal distribution of coverage among high ranked species, while communities near the bottom are unstable, having a simpler community structure owing to domination by a few species. Connell (1978) indicated that when disturbance is effective, community structure becomes simpler. Especially the $37 \mathrm{~A}$ sample may be regarded as a more matured community because of more massive growth of C. nippona.

As to the climax community of sessile invertebrates on artificial plates, Sutherland \& Karlson (1977), Sutherland $(1974,1978)$ and Osman (1977) observed that the communities were dominated by bryozoans, sponges or solitary ascidians, but not by oysters or mussels. Because the same single species does not dominate experimental plates, these results indicate that historical differences in colonization or disturbance occurring during succession allows the development of different dominant species. Sutherland (1974) pointed out that multiple stable points could exist in his system, while Osman (1977) described dominance by a single species as a stable endpoint. According to Osman (1977), unless physically disturbed the species composition will persist, so that historical differences at settlement bring about domination of different species, i.e. a group of stable endpoints. Sutherland (1974) and Osman (1977) immersed the plates at different seasons throughout the year. I did not try to immerse the plates at other seasons than summer. The change of community structure from Stage 1 to Stage 2 and Stage 3 does not necessarily occur if the experiment is started in the winter season. The abundant recruitment of barnacles which characterized Stage 1 occurs mainly in the summer in Nabeta Bay, so that the initial stage of succession initiated in winter will probably be dominated by other species. It is not likely that this species will 
continue to inhibit the recruitment of barnacles completely over $1 \mathrm{yr}$, because an abundance of barnacle larvae probably makes it possible for them to recruit even on a small unoccupied space. Settlement of Crassostrea nippona occurred more frequently on the shells of barnacles. Therefore, it is thought that recruitment of $C$. nippona will occur on the shells of barnacles, so long as these are present on the plates. $C$ nippona can settle on the shells of barnacles because of good recruitment; it can escape intensive overgrowth and has a long life span. These facts suggest that, unless effectively disturbed, communities of sessile invertebrates gradually become an oyster assemblage, and that the oyster assemblage will become a persistent climax community in spite of the seasonal difference caused by the time of immersion of experimental plates. The single climax dominated by $C$. nippona differs from the results of Sutherland (1974) and Osman (1977) who respectively found the destinations of their community development as multiple stable points and a group of stable points. Basically, communities of sessile organisms submerged at different times should converge on an equilibrium assemblage of the longestlived species, if they are not disturbed by physical or biological factor (Glasser 1982). C. nippona is not dominant on neighboring natural rocky reefs, but artificial structures such as concrete breakwaters frequently showed a monoculture of C. nippona over their surface.

As with oysters mentioned above, mussels also possess a fairly long life span and can escape intensive overgrowth, so that they appear to be able to evolve towards a climax dominated by only one species when there is no effective disturbance (Paine 1966, 1971, 1974, Dayton 1971. Menge 1976). However, mussels could not dominate plates immersed in the subtidal zone in the present study, the reason for which must be sought in a future investigation.

Acknowledgements. I thank Dr J. Mishima, Institute of Biological Sciences, University of Tsukuba, for suggesting this study and for constant guidance during the course of the work. I am very grateful to Dr L. R. Pomeroy, Institute of Ecology, University of Georgia, and Dr S. Nishiwaki, College of Medical Technology and Nursing, University of Tsukuba, for their valuable comments on the manuscript. Thanks are also due to Dr S. Mawatari, a former member of National Science Museum, Tokyo, Dr M. Imajima, of the same Museum, Dr T Nishikawa, Nagoya University, and M. S. H. Minegishi, Senior High School of Japan Women's University, for identifications. Finally, I am much indebted to staff members of Shimoda Marine Research Center for their great assistance during the course of this study.

\section{LITERATURE CITED}

Aleem, A. A. (1957). Succession of marine fouling organisms on test panels immersed in deep-water at La Jolla, California. Hydrobiologia 11: 40-58
Bakus, G. J. (1966). Some relationships of fishes to benthic organisms on coral reefs. Nature, Lond 210; 280-284

Connell, J. H., Slatyer, R. O. (1977). Mechanisms of succession in natural communities and their role in community stability and organization. Am. Nat. 111: 1119-1144

Connel, J. H. (1978). Diversity in tropical rain forests and coral reefs: high diversity of trees and corals is maintained only in a nonequilibrium state. Science 199: 1302-1310

Dayton, P. K. (1971). Competition, disturbance, and community organization: the provision and subsequent utilization of space in a rocky intertidal community. Ecol. Monogr. 41: 351-389

Drury, W. H., Nisbet, I. C. T. (1973). Succession. J. Arnold Arbor. 54: 331-368

Foster, M. S. (1975). Algal succession in a Macrocystis pyrifera forest. Mar. Biol. 32: 313-329

Glasser, J. W. (1982). On the causes of temporal change in communities: modification of the biotic environment. Am. Nat. 119: $375-390$

Hewatt, W. G. (1935). Ecological succession in the Mytilus californianus habitat as observed in Monterey Bay, California. Ecology 16: 244-251

Hirata, T. (1986). Succession of sessile organisms on experimental plates immersed in Nabeta Bay, Izu Peninsula, Japan. I. Algal succession. Mar. Ecol. Prog. Ser. 34: 51-61

Horn, H. S. (1966). Measurement of 'overlap' in comparative ecological studies. Am. Nat. 100: 419-424

Horn, H. S. (1974). The ecology of secondary succession. Ann. Rev. Ecol. Syst. 5: 25-37

Hoshiai, T. (1959). Synecological study on intertidal communities. II. On the interrelation between the Hijikia fusiforme zone and the Mytilus edulis zone. Bull Mar. Biol. Stn Asamushi, Tohoku Univ. 9: 123-126

Hoshiai, T. (1960). Synecological study on intertidal communities. III. An analysis of interrelation among sedentary organisms on the artificially denuded rock surface. Bull. Mar Biol. Stn Asamushi, Tohoku Univ. 10: 49-56

Hoshiai, $T$ (1965). Synecological study on intertidal communities. VI. A synecological study on the intertidal zonation of the Asamushi coastal area with special reference to its re-formation. Bull. Mar. Biol. Stn Asamushi, Tohoku Univ. 12: 93-126

Iwaki, T., Hibino, K., Kawahara, T. (1977). Seasonal changes in the initial development of fouling communities in Matoya Bay. Rep. Fac. Fish., Pref. Univ. Mie 4: 11-29

Kitazawa, T. (1967). Asexual reproduction in Leptoclinum mitsukurii (Oka) (Ascidiae Compositae). Sci. Rep. Tokyo Kyoiku Daig. Sec. B. 13: 31-50

Margalef, R. (1968). Perspectives in ecological theory. Univ. of Chicago Press, Chicago

McDougall, K. D. (1943). Sessile marine invertebrates of Beaufort, North Carolina: a study of settlement, growth, and seasonal fluctuations among pile-dwelling organisms. Ecol. Monogr. 13: 321-374

Menge, B. A. (1976). Organization of the New England rocky intertidal community: role of predation, competition, and environmental heterogeneity. Ecol. Monogr. 46: 355-393

Möbius, K. (1877). Die Auster und die Austemwirtschaft. Hempel \& Parrey, Berlin

Mook, D. H. (1981). Effects of disturbance and initial settlement on fouling community structure. Ecology 62: 522-526

Odum, E. P. (1969). The strategy of ecosystem development Science 164: 262-270

Osman, R. W. (1977). The establishment and development of a marine epifaunal community. Ecol. Monogr. 47: 37-63

Paine, R. T (1966). Food web complexity and species diversity. Am. Nat. 100: 65-75 
Paine, R. T. (1971). A short-term experimental investigation of resource partitioning in a New Zealand rocky intertidal habitat. Ecology 52: 1096-1106

Paine, R. T. (1974). Intertidal community structure: experimental studies on the relationship between a dominant competitor and its principal predator. Oecologia (Berl.) 15: 93-120

Scheer, B. T (1945). The development of marine fouling communities. Biol. Bull. mar. biol. Lab., Woods Hole 89 $103-121$

Stephenson, W., Searles, R. B. (1960). Experimental studies on the ecology of intertidal environments at Heron Islands. I. Exclusion of fish from beach rock. Aust. J. mar. Freshwat. Res. 11: 241-267

Sutherland, J. P. (1974). Multiple stable points in natural communities. Am. Nat. 108: 859-873

Sutherland, J. P. (1978), Functional roles of Schizoporella and Styela in the fouling community at Beaufort, North Carolina. Ecology 59: 257-264
Sutherland, J. P., Karison, R. H. (1977). Development and stability of the fouling community at Beaufort, North Carolina. Ecol. Monogr. 47: 425-446

Tsuchiya, M., Hirano, Y. (1985). Distribution of intertidal animals and associated fauna of the patch of the oyster Crassostrea gigas on the rocky shore of Mukaishima Island, Hiroshima, southwestern Japan. Bull. Biol. Soc Hiroshima Univ. 51: 3-9

Tsuchiya, M., Osanai, K. (1978). Experimental marine organisms collected in the neighborhood of the Asamushi Marine Biological Station. Bull. Mar. Biol. Stn Asamushi, Tohoku Univ. 16: 29-58

Yamaguchi, M. (1975). Growth and reproductive cycles of the marine fouling ascidians Ciona intestinalis, Styela plicata, Botrylloides violaceus, and Leptoclinum mitsukurii at Aburatsubo-Moroiso Inlet (Central Japan). Mar. Biol. 29: 253-259 